\title{
AVALIAÇÃP PÓS-OCUPACIONAL DO CAMELÓDROMO/PRAÇA DA BANDEIRA NA CIDADE DE PRESIDENTE PRUDENTE-SP
}

\author{
Maria Alessandra Bacaro Boscoli ${ }^{1}$, Gabriela Bianchi Lanzetta ${ }^{2}$, Lana Mika Ota ${ }^{2}$ \\ ${ }^{1}$ Docente do Curso de Arquitetura e Urbanismo da UNOESTE. ${ }^{2}$ Discente do Curso de Arquitetura e Urbanismo da \\ UNOESTE. E-mail: allyboscoli@gmail.com
}

\section{RESUMO}

Presidente Prudente é uma cidade no interior paulista que assim como todas as outras cidades está sujeita a modificações de seus espaços. Neste trabalho refletiremos sobre uma dessas transformações, a Praça da Bandeira que se tornou um camelódromo, e verificaremos a qualidade do espaço produzido e modificado a partir da mesma. Tomando como exemplos espaços voltados para os mesmo fins em outros locais, em normas técnicas e autores que discutem o crescimento e elementos de identificação das cidades buscamos compreender o processo de produção destes espaços e avaliar o uso que acontece atualmente depois de vários anos de ocupação e evolução de apropriação.

Palavras-chave: Camelódromo, Praça da Bandeira, Avaliação pós-ocupacional, Centro, Presidente Prudente.

\section{INTRODUÇÃO E OBJETIVO}

Presidente Prudente é uma cidade localizada no oeste do estado de São Paulo, e assim como toda cidade sofre mudanças no decorrer do tempo. Este trabalho irá estudar uma dessas mudanças que é a transformação da Praça da Bandeira em um camelódromo.

Com a evolução da cidade construiu-se um viaduto que seria um símbolo do progresso, no entanto este trouxe sérias consequências que mudaram o desenho urbano da área, as duas praças, Praça da Bandeira e Praça Nossa Senhora Aparecida, antes interligadas foram separadas e cada uma seguiu um rumo diferente.

$\mathrm{O}$ alvo deste estudo, a Praça da Bandeira, se tornou um local de compras conhecido como camelódromo, com base em diversos autores, referências de outras localidades e normas brasileiras avaliaremos este espaço depois de criado e ocupado.

Quando adentramos o espaço em questão, é notável o desconforto térmico, os sons ao redor, a grande quantidade de informação visual, o caos espacial e falta de acessibilidade, no entanto podemos perceber também que o espaço é utilizado intensamente, o que nos leva a pensar que a transformação tenha sido benéfica, pois o local não ficou abandonado, ao contrário da parte remanescente da Praça da Bandeira que mantém bancos, brinquedos e vegetação porém quase sem vida, se tornando uma área marginalizada. 
Esse estudo tem a intenção de analisar como se encontra a atual situação dessa estrutura que foi feita na década de 90, observando a adequação do espaço, a infraestrutura e analisar a acessibilidade e mobilidade urbana.

\section{METODOLOGIA}

O trabalho foi realizado através de levantamentos históricos, sócio-econômicos, de infraestrutura, pesquisas documentais e fotográficas a fim de compreender o objeto de estudo. Os estudos foram feitos através de visitas técnicas com elaboração de croquis para entendimento da organização dos boxes na praça, levantamento métrico e fotográfico. Pesquisas em artigos científicos buscando entender a forma como o espaço se organizou e se modificou como passar dos anos. Além disso, foram analisadas normas de acessibilidade e referências de praças e seus diversos usos, assim como a comparação com camelódromos de outras cidades.

Para entendimento dos elementos que compõe a imagem da cidade, foram estudados textos de Kevin Lynch e Gordon Cullen. Também faz-se o uso da escrita de Jane Jacobs para avaliar a vitalidade da cidade e seus espaços.

\section{RESULTADOS}

A área de estudo está localizada na cidade de Presidente Prudente, cidade do interior do estado de São Paulo, entre o quadrilátero central e a Vila Marcondes. Nas proximidades de duas barreiras físicas que são a linha férrea e o Viaduto Coordenador Tannel Abud.

A linha férrea além de ser uma barreira física é também psicológica e fez com que a cidade desse as costas para a Vila Marcondes, se desenvolvendo para o sentido contrário a ela, segundo Jacobs:

As linhas férreas são um exemplo clássico de fronteira, tanto que passaram a significar, há muito tempo, também fronteiras sociais - "do outro lado da linha do trem" -, uma conotação, coincidentemente associada mais a cidades de pequeno porte [...] (JACOBS, 2009)

Da Praça Nossa Senhora Aparecida localizada na Vila Marcondes era possível ver a Praça da Bandeira, até a década de 70, quando foi implantado o viaduto a fim de mostrar desenvolvimento para a cidade, uma vez que nos EUA já havia acontecido o Federal-aid Highway Act que previa a construção de rodovias para promover a descentralização urbana e incentivar o uso do automóvel.

A construção do viaduto fez com que acabasse a visualização entre as praças, fragmentando também a cidade e a ligação que havia entre o Centro e a Vila Marcondes passa a 
ser por um túnel, que é utilizado como banheiro público e local para morador de rua dormir durante a noite.

Reconhecemos que as cidades mudam de acordo com as necessidades e mudanças de hábitos das pessoas. Jacobs (2000) também argumenta que não é possível conferir animação para uma quantidade muito grande de espaços públicos, Por isso, as áreas verdes defendidas pelo Movimento Moderno não funcionaram, tornando-se áreas vazias e sem apropriação por parte popular.

Adotando a praça a característica de espaço multifuncional e caracterizado por ser um ponto nodal de concentração, compreende-se a intervenção e mudança da Praça da Bandeira que antes tinha somente vegetação, os caminhos e mobiliários urbanos, em 1993 passa a abrigar o camelódromo com 98 box.

A nova configuração da praça é novamente explicada pela transferência de modelos americanos, que é criticada por Alex Sun, doutor pela FAU-USP, uma vez que as praças públicas referem-se as características de cada cultura urbana. Mas a inserção do camelódromo foi feita no contexto em que essa praça livre entrara em desuso, devido a mudança no cotidiano das pessoas e violência, as famílias começam tomar uso de espaços provados para a vida pública, como é o caso dos shoppings.

Em 2001, 144 comerciantes ambulantes que atuavam na áreas central foram remanejados e levados para o camelódromo, totalizando 242. Na época, esses comerciantes que se encontravam na rua ficaram insatisfeitos com a mudança, uma vez que eram vistos na rua por um público bem maior, e passaram a competir lado a lado com o Box vizinho, que muitas vezes tinham o mesmo tipo de mercadoria.

Atualmente encontram-se 271 box, mais alguns ambulantes que que montam banca ou trailer na calçada.

O camelódromo de Cuiabá no Mato Grosso está abrigado sob uma imensa estrutura de formato retangular, vazada nas laterais e com teto abobadado de folhas de alumínio, contém 400 barracas metálicas fixas distribuídas em quatro corredores, numeradas e pintadas de verde, todas exatamente iguais.

Até o ano de 1995, os camelôs eram "comerciantes de rua" fazendo uso de praças e ruas do centro da cidade para exercer suas vendas, depois foram obrigados, pela prefeitura, a se deslocar para uma área periférica no bairro do Porto se estabelecendo nessa estrutura. Assim como 
aconteceu com os ambulantes em Presidente Prudente, mas que nesse caso permaneceram no centro da cidade, inseridos na Praça da Bandeira.

Produz-se como espaço costumeiro de venda de mercadorias, mas principalmente, como lugar de contato com uma multiplicidade de fluxos (econômicos e culturais, sobretudo) os quais extrapolam a cidade, a região e o país, ao alcance das populações mais pobres, chamados de fluxos globais subalternos.

Já o camelódromo da Praça XV em Porto Alegre no Rio Grande do Sul é uma grande feira, estrutura viva que se move, se altera. São 420 bancas que adaptam e improvisam coberturas com lonas, utilizando as palavras de Aguiar (2009): caracterizam o modo de ser e agir, no cotidiano intenso da rua.

O camelódromo da Praça VX já era histórico, depois de 40 anos ocupando o centro histórico de Porto Alegre veio a notícia que teriam que se mudar e passar a ocupar um edifício a algumas ruas dali.

Em Presidente Prudente atualmente são 273 boxes, sendo 244 voltados para a venda de produtos e 29 para a alimentação (figura 1). Contando com poucos banheiros públicos, localizados nas extremidades, ponto de ônibus que também proporciona movimento e aumenta o fluxo de pessoas que passam por ali no decorrer do dia, e apenas um bebedouro que é o novo e já vinha sofrendo mal uso, foi desativada a água gelada porque era utilizados pelos próprios comerciantes para lavar pano usado para limpeza.

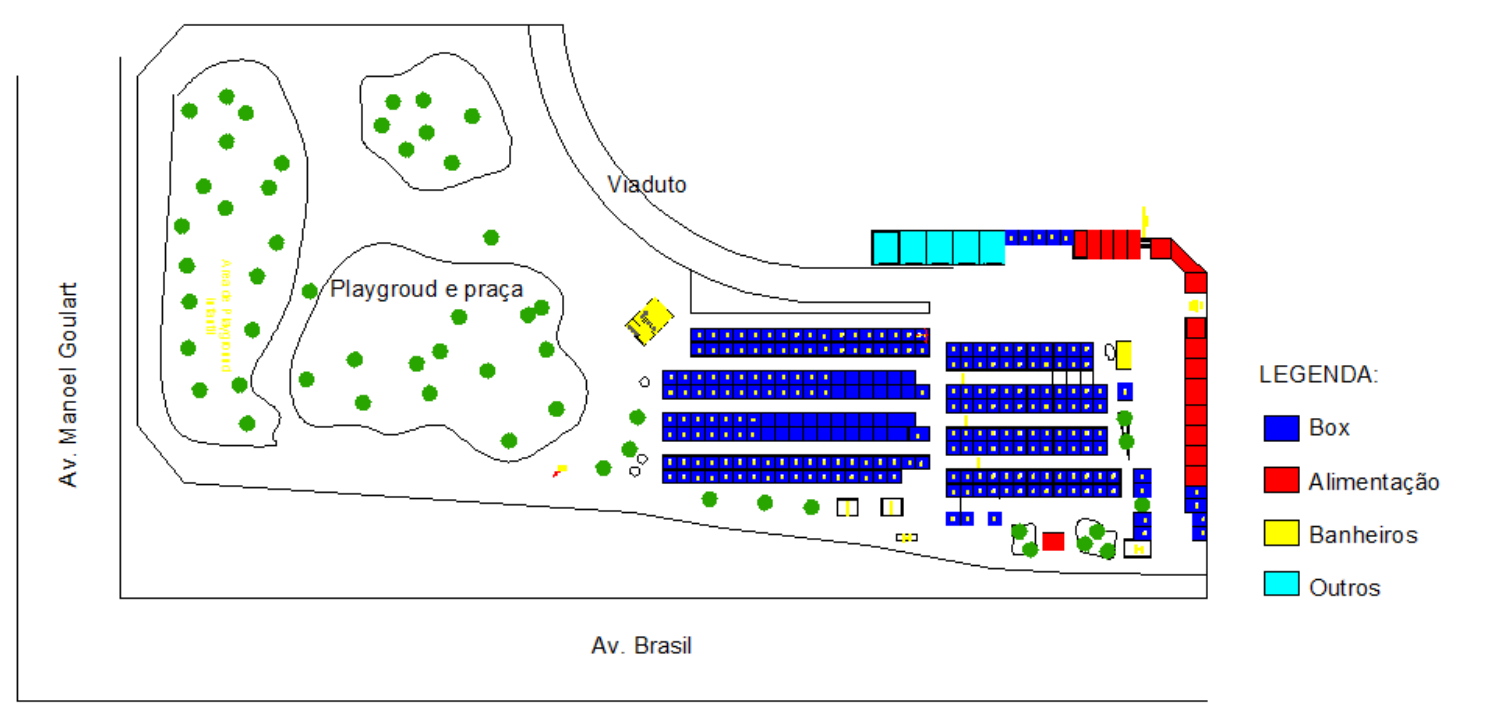

Figura 1. Croqui do local

Fonte: Autores, 2013 
Na parte de trás, logo abaixo do viaduto encontram-se: Alcoólicos anônimos, Conselho da Associação de Moradores de Presidente Prudente e SORPP. Percebe-se uma poluição visual pelas diferentes coberturas e pisos (figuras 2 e 3), uma vez que cada um fica responsável pela manutenção do seu Box e faz como quer, o lixo jogado na calçada, a ausência de cuidado com a vegetação no percurso todo, somente ass árvores muito antigas estão presentes no local, os grandes canceitos não tem a presenção nem de grama (figura 4). Essa falta de cuidado denota uma imagem de mal uso e denigre o local e o que as pessoas pensam dele.

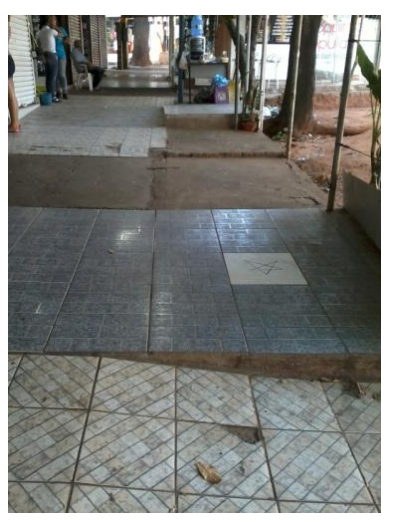

Figura 2. Diferentes pisos

Fonte: Arquivo dos autores
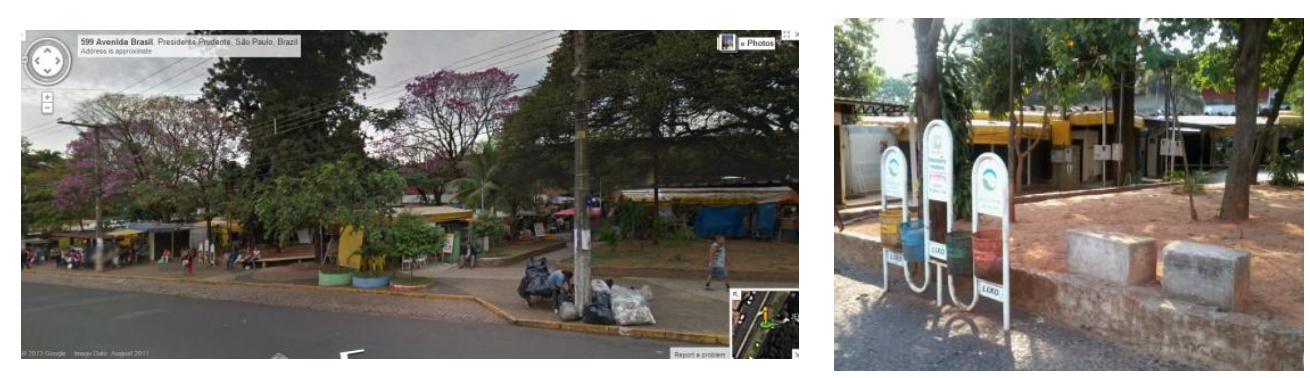

Figura 3. Coberturas diferentes Fonte: Google Street view
Figura 4. Canteiros

Fonte: Arquivo dos autores

O restante da praça se apresenta com total descuido quanto a jardinagem, o parque está com os bancos e brinquedos quebrados, totalmente sem manutenção.

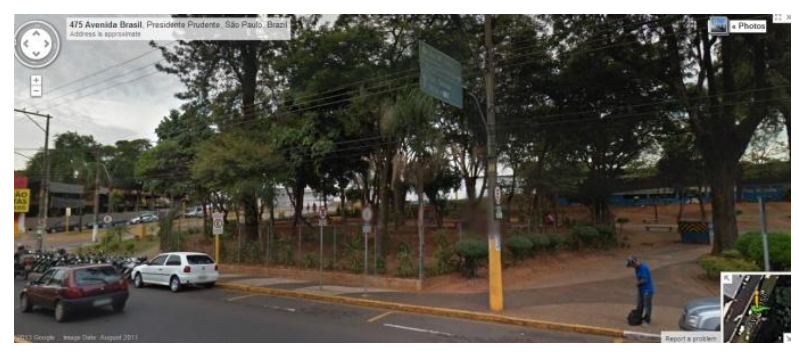

Figura 5. Remanescente da praça

Fonte: Google street view

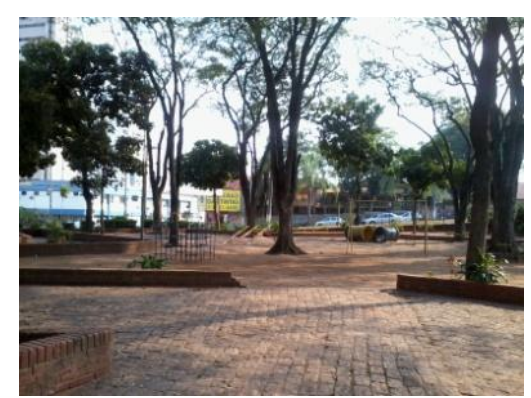

Figura 6. Remanescente da praça

Fonte: Arquivo dos autores

Durante o dia, o fluxo é extremamente intenso, tanto de veículos que passam pela avenida, quanto pedestres que circulam pelas ruas do centro, que passam ainda que seja somente para esperar o ônibus e aqueles que frequentam a praça para trabalhar ou consumir. 
No entanto, durante a noite, todas as lojas estão fechadas e no entorno da praça também a área do camelódromo é bem iluminada e possui um vigia noturno, encontram-se alguns pontos comerciais alimentícios abertos, mas no parque fica completamente escuro (figura 7), e a falta de vida da qual Jane Jacobs fala é refletida com uma série problemática nesse local: uso como reduto de usuários de droga.

Jacobs afirma que para não haver morte das áreas centrais nnos períodos noturnos deve ter diversidade, mantendo assim a vitalidade esperada, para isso ela diz:" [...] eficiência significa que a mistura de pessoas na rua em determinado momento do dia deve ser razoavelmente proporcional ao número de pessoas em outros horários do dia" (JACOBS, 2009).

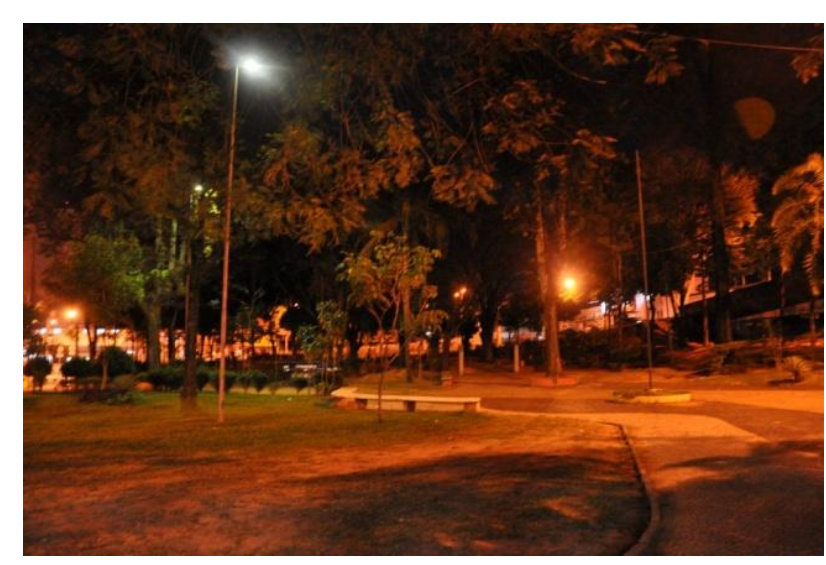

Figura 7. Praça durante a noite Fonte: arquivo dos autores

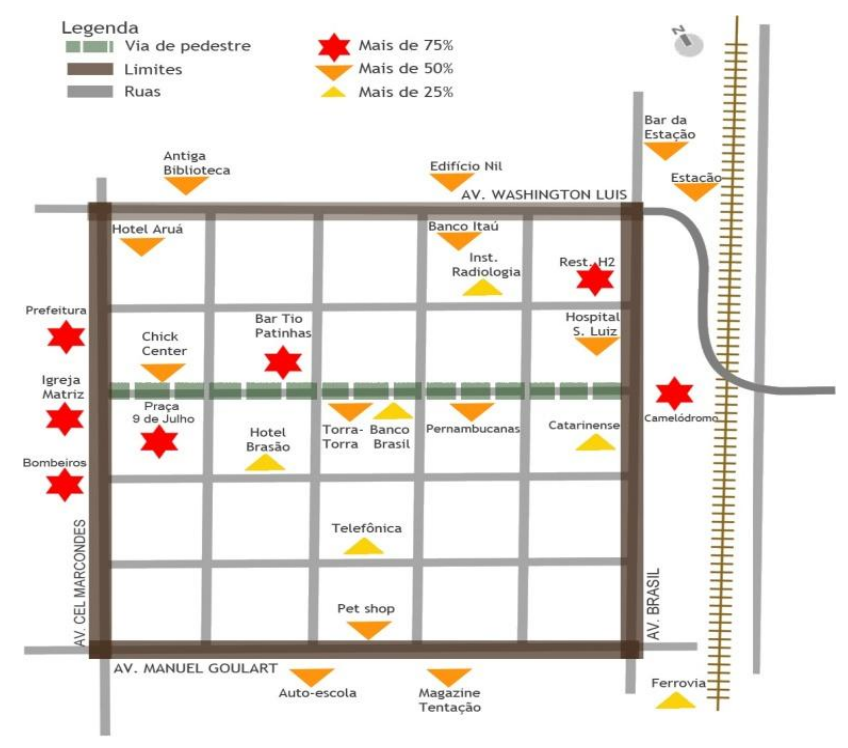

Figura 8. Mapa mental

Fonte: Shwambach, Assad, Lanzetta

Buscando a identificação dos elementos que compõe a identidade da cidade, foram aplicadas metodologias de Kevin Lynch (1999) através da elaboração de mapas mentais e leitura da cidade. Resultado que as pessoas têm na memória do centro da cidade, para elas o camelódromo é um ponto de referência, um marco.

\section{DISCUSSÃO}

O trabalho realizado possibilitou o estudo da transformação da cidade e da apropriação de um espaço público de uma praça em um centro de comércio popular.

Ao realizar uma visita ao local somos dominados pelo desconforto: o local é extremamente quente, pessoas nos abordam a cada passo e pouco espaço para caminhas, uma vez que as mercadorias invadem os corredores. O resquício da praça está esquecido, como se fosse algo que não existe, além de ser um espaço cercado em decorrência às vias adjacentes ao espaço que oferecem risco. 
O que antes era uma praça que unia os dois primeiros bairros da cidade, após a construção do viaduto segregou um do outro. Espaços foram criados embaixo do viaduto, a Praça da Bandeira se tornou um shopping popular, mas apesar de tudo são inúmeros os motivos que nos levam a acreditar que a intervenção poderia ter sido diferente.

A praça arborizada foi dominada por telhas de fibrocimento e apertados boxes que não comportam os produtos que vendem.

Acessibilidade é algo que não se encontra, uma vez que o lugar está tomado de degraus, desníveis e obstáculos que dificultam a locomoção e não segue em forma alguma a norma de acessibilidade NBR 9050.

O maior questionamento dos autores deste trabalho é como um espaço que oferece tantas dificuldades de locomoção e tanto desconforto têm como atrativo para gerar uma vida pulsante, mesmo que durante o período noturno haja uma redução drástica no fluxo de pessoas.

Toda via vale lembrar que o camelódromo é fonte de renda para centenas de pessoas, oferece empregos e também produtos diversificados com preços mais atrativos do que os oferecidos em outros comércios, e que estes são provavelmente os principais atrativos do local.

\section{CONCLUSÃO}

Neste trabalho pudemos estudar a maneira em como um objeto de ostentação do desenvolvimento da cidade como o viaduto Tannel Abud pode modificar radicalmente um espaço, as praças Nossa Senhora Aparecida e da Bandeira que antes eram conectadas e serviam como um local de encontro e passagem foram separadas.

Em decorrência da separação surge algo novo, um camelódromo que é uma atração na cidade, um marco, um ponto nodal que gera renda e empregos, que oferece produtos diversificados. O resquício da praça é pouco frequentado, é cercado pois devido a evolução da cidade o transito ao redor se tornou um risco à segurança dos frequentadores deste espaço.

Vale ressaltar que duas praças foram separadas, e apenas uma foi objeto e nosso estudo, não levando em consideração o que está do outro lado do túnel que serve de conexão entre as duas.

Mostrando uma vida mais intensa, a parte do camelódromo aparenta ser um grande acerto na transformação do espaço, mesmo que a qualidade do espaço criado não seja adequado do ponto de vista do conforto ambiental e de mobilidade, um espaço que se adaptou as transformações que ocorreram e que ocorrem durante a evolução e o crescimento da cidade. 


\section{REFERÊNCIAS}

AGUIAR, Julia Saldanha Oliveira. Por uma cidade que se move: rua, corpo e improviso. Vitruviusarquitextos número 106.03ano 09, mar 2009

ASSOCIAÇÃO BRASILEIRA DE NORMAS TÉCNICAS. NBR 9050: Acessibilidade a edificações, mobiliário, espaços e equipamentos urbanos. Rio de Janeiro, 2004.

BRANDÃO, Ludmila. O "camelódromo", a cidade e os fluxos globais subalternos. São Paulo, Pós v.16 n.25, junho 2009.

FERREIRA, C. A. Os Vendedores ambulantes do centro de Presidente Prudente: uma contribuição ao estudo da economia informal. 1999. $75 \mathrm{f}$.

Trabalho de Conclusão de Curso (Graduação em Geografia) - Faculdade de Ciências e Tecnologia, Universidade Estadual Paulista, Presidente Prudente, 1999.

GREGÓRIO, Daniele Aparecida Gonçalves. Camelôs, camelódromo e informalidade: um estudo sobre o trabalho informal no comércio de Presidente Prudente. Monografia de GraduaçãoFaculdades integradas “Antônio Eufrásio de Toledo" - Presidente Prudente, 2002.

JACOBS, Jane. Morte e Vida de Grandes Cidades. São Paulo: Editora Martins Fontes, 2009.

LYNCH, Kevin. A Imagem da Cidade. São Paulo: Editora Martins Fontes, 2010.

OLIVEIRA, Carlos Alberto. A praça no centro do debate: Desenho social, político e cultural. Vitruvius- resenhas on line número 110.02 ano 10, fev 2011.

ORNSTEIN, Sheila. Avaliação pós ocupação do ambiente construído. São Paulo: Studio Nobel, 1992.

SABOYA, Renato. Jane Jacobs e os parques de bairro. Site urbanidades: Urbanismo, Planejamento Urbano e Planos diretores. Setembro 2007. 